\title{
Harmonisation of biobanking standards in endometrial cancer research
}

\author{
M Adishesh ${ }^{1,2}$, A Fyson $^{2}$, S B DeCruze ${ }^{1}, \mathrm{~J} \mathrm{Kirwan}^{1}$, ENITEC Consortium, H M J Werner ${ }^{3,4}$ and \\ D K Hapangama*,1,2 \\ ${ }^{1}$ Liverpool Women's Hospital NHS Foundation Trust, Crown Street, Liverpool L8 7SS, UK; ${ }^{2}$ Department of Women's and Children's \\ Health, Institute of Translational Medicine, University of Liverpool, Liverpool Women's Hospital, Crown Street, Liverpool L8 7SS, \\ UK; ${ }^{3}$ Department of Obstetrics and Gynaecology, Haukeland University Hospital, Jonas Liesvei 70, 50503 Bergen, Norway and \\ ${ }^{4}$ Department of Clinical Science, University of Bergen, Bergen 5021, Norway
}

\begin{abstract}
Background: Endometrial cancer is the most common gynaecological cancer and its incidence is predicted to escalate by 50-100\% in 2025 with a parallel increase in associated mortality. Variations in the collection, processing and storage of biospecimens can affect the generalisability of the scientific data. We aimed to harmonise the collection of biospecimens, clinical data relevant to endometrial cancer and to develop standard operative procedures for the collection, processing and storage of endometrial cancer biospecimens.
\end{abstract}

Methods: We designed research tools, which were evaluated and revised through three consensus rounds - to obtain local/ regional, national and European consensus. Modified final tools were disseminated to a panel $(n=40)$ representing all stakeholders in endometrial cancer research for consensus generation.

Results: The final consensus demonstrated unanimous agreement with the minimal surgical and patient data collection tools. A high level of agreement was also observed for the other remaining standard tools.

Conclusions: We here present the final versions of the tools, which are freely available and easily accessible to all endometrial cancer researchers. We believe that these tools will facilitate rapid progress in endometrial cancer research, both in future collaborations and in large-scale multicentre studies.

Endometrial cancer (EC) is the most common cancer of the female genital tract in the developed world, and is the fourth most common cancer in women after breast, lung and colorectal cancer (Ferlay et al, 2015). In the United Kingdom in 2014, at least 6 women died of and 21 women were diagnosed with EC in the United Kingdom every day, with 9022 new cases and 2166 deaths reported that year (CRUK). The incidence rate of EC is increasing rapidly and is estimated to increase by $50-100 \%$ by 2025 (Lindemann et al, 2010). This increase in incidence is alarming, particularly due to the corresponding rise in mortality (CRUK). Increased efforts into finding new prevention, diagnostic, prognostic and therapeutic targets are therefore urgently required to reduce the high mortality and morbidity rates associated with EC. Traditionally, among others immunohistochemistry was used, based on formalin-fixed paraffin-embedded tissue, allowing only for the study of a limited number of proteins simultaneously. Further cell lines and animal studies have been applied in EC research; these however rarely give a perfect simulation of the in vivo human environment. Therefore, biobanks, collecting a wide range of different patient specimens, including for example fresh frozen tissue, urine, blood or saliva, have a vital role in providing valuable patient material for clinically relevant scientific discoveries and also aid to the rapid translation of basic scientific findings to clinical practice.

Through its nature, patient material stored in biobanks allows for studying multiple aspects of EC. This is of paramount importance with the emergence of novel technological platforms in genomics, proteomics, epigenomics and metabolomics that can be collectively and simultaneously applied to the same patient samples to gain the maximum amount of information. Such an all- 
encompassing approach is expected to reduce considerably the time taken for new basic scientific discoveries to reach patients as new treatments as well as allowing the samples donated by patients to be fully used.

The internal and external validity of the generated data depend on their quality, which is clearly dependent on the use of stringent standards in collecting the biospecimens and patient characteristics. Variations associated with collecting, processing, storing different biospecimens and the accompanying phenotypic and demographic data make it extremely difficult to extrapolate or to merge data from different studies (Tworoger and Hankinson, 2006; Ransohoff and Gourlay, 2010). This lack of quality standards and uniformity is recognised by the National Cancer Institute (NCI) as a roadblock in cancer research (NCI Best Practices for Biospecimen Resources, 2011). The irrevocable bias introduced by the irregularities and dissimilarities in specimens and data collection are well recognised by many and efforts are being made to overcome this by several international organisations and agencies (Morente et al, 2007; International Society for Biological and Environmental Repositories, 2008; Yuille et al, 2008; Vaught and Lockhart, 2012).

The NCI best practice guidance for biobanks (NCI Best Practices for Biospecimen Resources, 2011, 2016), which encourages optimisation of the resources available for cancer research, broadly mentions a limited list of preanalytic variables related to the donor or sample collection/processing. It has thereby been effective in raising the overall awareness and quality of research involving biospecimens.

Although this is an important start, many parameters and variables of interest, including choice of biospecimens and clinical data, are cancer-type-specific. Thus, universal biobanking standards are not necessarily applicable to every cancer type and should be adapted to each specific disease. The importance of cancer-specific harmonisation of biobanking standards is highlighted by the cancer genome atlas (Kandoth et al, 2013), which now contains over 532 EC samples with RNA sequencing, copy number variation, proteomic, mutation and microarray data. However, the extremely limited clinical data accompanying most of these samples and data sets severely affects the ability of researchers to draw clinically applicable information.

Therefore, EC-specific standardisation of the collection of biospecimens with distinctive and relevant accompanying clinical data sets is a fundamental unmet need in improving future EC research. This, we believe, will facilitate future large-scale internationally collaborative research into EC, which could lead to improved biomarker and target treatment discovery. Similar harmonisation projects have already been successfully implemented for other gynaecological conditions such as endometriosis World Endometriosis Research Foundation Endometriosis Phenome and Biobanking Harmonisation Project and Ovarian Cancer Research Program (Wiegand et al, 2010; Heravi-Moussavi et al, 2012; Fassbender et al, 2014; Rahmioglu et al, 2014; Vitonis et al, 2014).

With this background, we initiated our study (Harmonisation of biobAnking STandards in Endometrial caNcer research - HASTEN) to achieve consensus among EC researchers; standardise the collection, processing and storage of all relevant biospecimens; and the accompanying clinical data for EC research through a joint effort with patients, surgeons/physicians/pathologists and the personnel of biobanks. We aimed to develop standards: standard operative procedure tools with a minimum and standard data set to be regularly updated and universally available for future researchers in EC.

\section{MATERIALS AND METHODS}

The method used to design the final tools in HASTEN is summarised in the flow diagram (Figure 1). We used a modified Delphi system to analyse and confirm the final consensus.

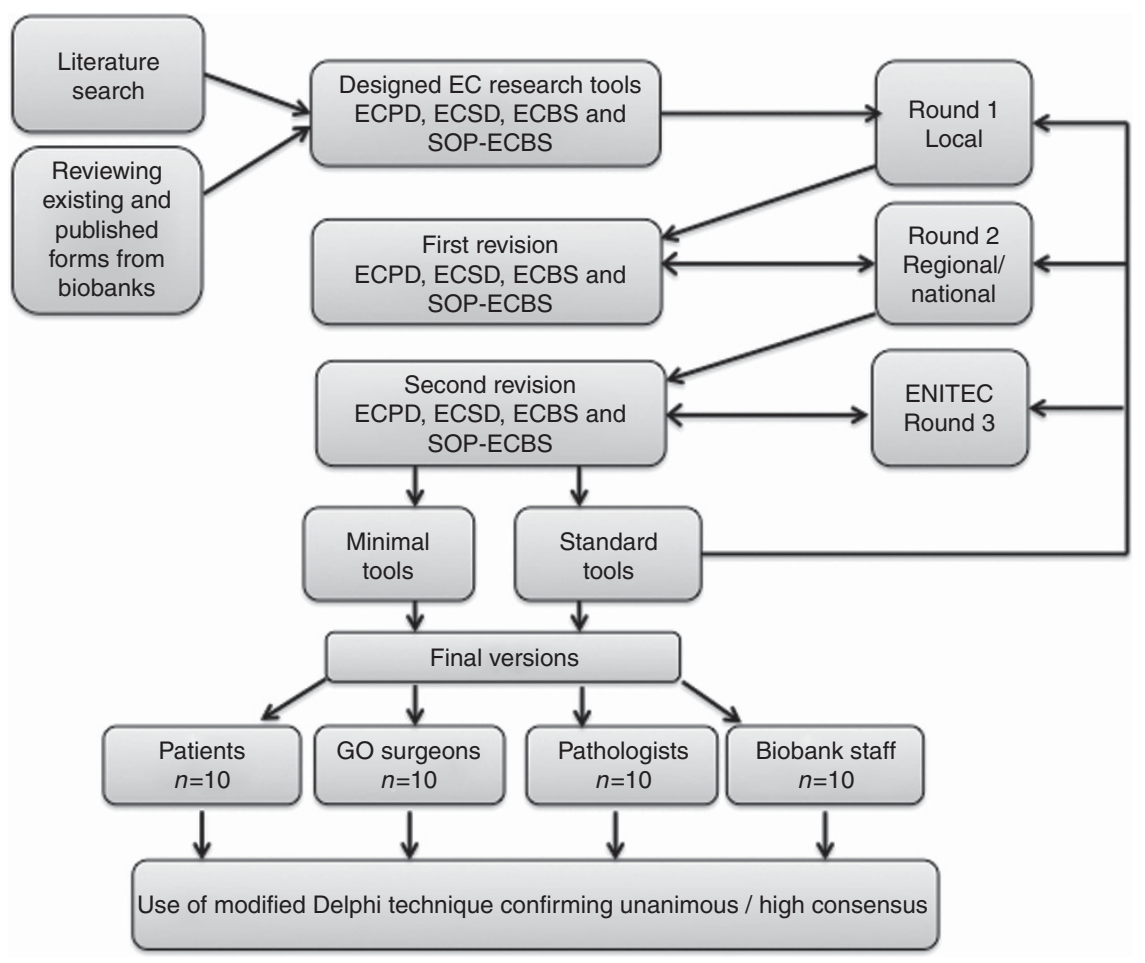

Figure 1. Flow chart illustrating our workflow in designing the EC research tools and the method of generating consensus (Endometrial cancer (EC), European Network of Individualised Treatment in Endometrial Cancer (ENITEC), Endometrial Cancer Patient Data Collection Tool (ECPD), Endometrial Cancer Surgical Data Collection Tool (ECSD), Endometrial Cancer Biospecimen Tool (ECBS), standard operating procedure for collection, processing and storage of tissue and fluid for EC research (SOP-ECBS)). 


\section{Generation of the initial tools}

Literature search. We performed a systematic review of the literature using the keywords 'Endometrial Cancer', 'risk factors', 'age of presentation', 'parity', 'menopausal status', 'metformin', 'progestogens or Mirena', 'hormone replacement therapy', 'polycystic ovary syndrome', 'tamoxifen', 'bowel cancer', 'colorectal cancer', 'breast cancer', 'diabetes', 'hypertension', 'ethnicity', 'anthropometric assessment', 'smoking', 'standard operating procedure' and 'endometrium', 'blood or plasma or serum', 'saliva', 'urine', 'endometrial fluid', 'peritoneal fluid', 'biobank best practices' 'histopathology markers', 'outcomes', 'biomarkers', 'Laboratory processing procedures of tissue, blood and body fluids', 'biobanking standards', 'SOP's for collection of tissue, fluids, blood, saliva, urine' in Scopus, Discover and PubMed databases. The literature search was limited to studies published in the past 10 years. Out of 3464 papers identified in the initial search, 413 papers were selected for further detailed scrutiny based on the following inclusion criteria:

(1) Papers that investigated how the aforementioned factors affect an individual's risk of developing EC.

(2) Publications that proposed standard operating procedures (SOPs) or best practices for the collection, storage and processing of the different tissues or fluids.

(3) Papers in English language only.

(4) Papers available as full text via all available resources to the authors (e.g., online resources or library facilities at Liverpool Women's Hospital (LWH), University of Liverpool, British Medical Association or Royal College of Obstetricians and Gynaecologists.

We further conducted manual searches for the relevant manuscripts referenced in these selected papers and the relevant guidelines from the large biorepositories.

\section{FURTHER DEVELOPMENT OF THE TOOLS}

First local consultation. The local team at Liverpool, comprising of four members of surgical gynaecological oncology team, four Macmillan clinical cancer nurse specialists, two clinical academics with an interest in EC research, two pathologists, two biobank staff members and a medical student, developed the three forms (patient data collection tool, surgical data collection tool, biospecimen form) and a standard operative procedure. These forms and the SOP were based on: (a) the information gathered in the literature search; (b) by considering the forms that were already in use in LWH/University of Liverpool biobank to collect biospecimens and data in EC research studies. Liverpool Women's Hospital is a tertiary referral regional cancer centre for gynaecological cancers, and is part of the Cheshire and Merseyside strategic clinical networks, which serves a population of 2.4 million. The age-standardised incidence rate of EC in the Merseyside and Cheshire cancer network is 18.3 per 100000 female members of the population (NCIN, 2013; Gynae Clinical Network Constitution, 2014-2015). (c) Standard operating procedures developed by the National Institutes of Health, Human Endometrial Tissue and DNA Bank for the collection, transport and storage of human endometrial tissue and blood samples of women undergoing endometrial biopsy or hysterectomy for non-malignant indications (Sheldon et al, 2011). (d) Sample handling and storage protocol published by the UK biobank to collect urine and blood samples (Elliott et al, 2008). UK biobank is a major national and international health resource, which was established by Wellcome trust, Medical Research Council, Department of Health, Scottish Government and The Northwest Regional Development Agency.
The main aim of this was to improve prevention, diagnosis and treatment of many illnesses such as cancer, heart disease, stroke, diabetes, arthritis, osteoporosis and dementia.

The forms were revised and amended based on local consultation.

Second regional/national consultation. The modified versions of the three forms and the SOP mentioned above were disseminated among three regional and eight national research centres involved in EC research in the United Kingdom and forms were revised integrating their feedback and as a result, two different tools, a minimal and a standard tool were developed. This pragmatic and inclusive approach provides guidance for collecting either a minimal or the ideal 'standard' data set considering the available resources.

Third European consultation. The modified forms were then circulated to all researchers adhering to the European Network of Individualised Treatment in Endometrial Cancer (ENITEC) and were further revised according to feedback received. The revised tools were presented at the annual ENITEC face-to-face meeting in June 2016, where the minimal form was unanimously approved by all 47 attendees. Some further modifications were suggested for the standard tool, which was revised accordingly and the revised forms were repopulated to all participated in the consultations rounds 1-3 to obtain their final approval.

Consensus generation. A modified Delphi system was used to generate consensus regarding the final adapted tools. For this, the forms were disseminated to a group of selected panel members of representing all stakeholders included in all previous rounds, including patients, gynaecological oncologists, researchers, pathologists and biobank staff, randomly selected from the participants of the consultation $(n=40)$ to evaluate and score the tools using a scoring sheet recording their agreement.

Statistical analysis. The consensus was quantified using a modified Delphi technique and we have reported the median with an interquartile range and also percentages for each category of the Likert scale. A nine-point Likert scale was used, except for the patient data tool where the scale was reduced to five points to reduce complexity for patients.

\section{RESULTS}

\section{Final tools}

ECPD collection tool. A patient-friendly data collection tool (EC patient data (ECPD)) was devised to capture many important demographic variables that are directly relevant to EC research that can only be accurately recalled by the patient herself. For example, the available literature suggests that $>20 \mathrm{~kg}$ of adult weight gain to be independently associated with increased risk of EC (Friedenreich et al, 2007) and this information is unlikely to be obtained easily other than directly from the patient. Many other risk factors for EC such as the age of presentation, the postmenopausal status, polycystic ovarian disease (Fearnley et al, 2010), nulliparity (Schonfeld et al, 2013), early age of menarche (Gong et al, 2015), family history of hereditary lynch syndromerelated cancers (Boilesen et al, 2008), past history of lynch syndrome-related cancers, medical conditions such diabetes (Friberg et al, 2007), previous use of tamoxifen (Bergman et al, 2000), hormone replacement therapy use (Beral et al, 2005) and exercise habits have been included in the tool. Some other factors with inconclusive links to EC at present such as smoking (Lindemann et al, 2008) were also included in anticipation of their confirmation in appropriate future studies. Table 1 and Figure 2 illustrate the outcome of the final round of consensus. 
Table 1. Outcome of the final round of consensus for ECPD Tool using 5-point Likert scale

\begin{tabular}{|c|c|c|c|c|c|c|}
\hline \multirow[b]{2}{*}{ Statements in the score sheet for patients } & \multirow[b]{2}{*}{$\begin{array}{c}\text { Score, } \\
\text { median (IQR) }\end{array}$} & \multicolumn{5}{|c|}{ Percentages of responses (\%) } \\
\hline & & $\begin{array}{l}\text { Strongly } \\
\text { agree }\end{array}$ & Agree & Undecided & Disagree & $\begin{array}{l}\text { Strongly } \\
\text { disagree }\end{array}$ \\
\hline The information asked in personal history is easy to fill & $1(1-2)$ & 60 & 40 & 0 & 0 & 0 \\
\hline $\begin{array}{l}\text { The questions in medical history section are easy to } \\
\text { understand and fill }\end{array}$ & $1(1-2)$ & 60 & 40 & 0 & 0 & 0 \\
\hline The questions in past history are easy to understand and fill & $1(1-2)$ & 60 & 40 & 0 & 0 & 0 \\
\hline $\begin{array}{l}\text { The questions in social history section are easy to understand } \\
\text { and fill }\end{array}$ & $1(1-2)$ & 60 & 30 & 10 & 0 & 0 \\
\hline $\begin{array}{l}\text { Overall, the form is easy to understand and does not take } \\
\text { much time to fill it }\end{array}$ & $1.5(1-2)$ & 50 & 50 & 0 & 0 & 0 \\
\hline
\end{tabular}

A

Statistical analysis of ECPD tool (median with interquartile range)

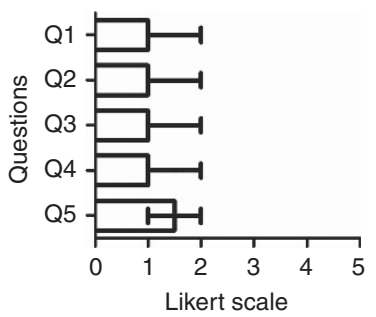

B

Statistical analysis of ECSD tool (median with interquartile range)

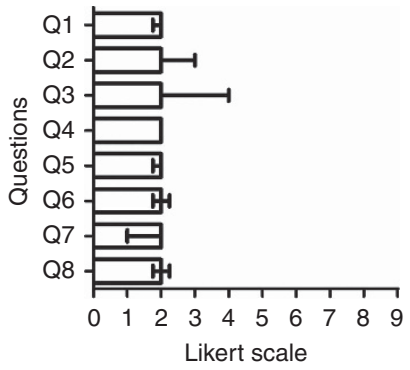

C

Statistical analysis of ECBS tool (median with interquartile range)

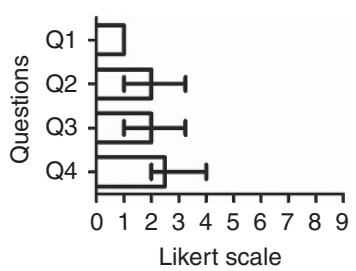

D

Statistical analysis of SOP-ECBS tool (median with interquartile range)

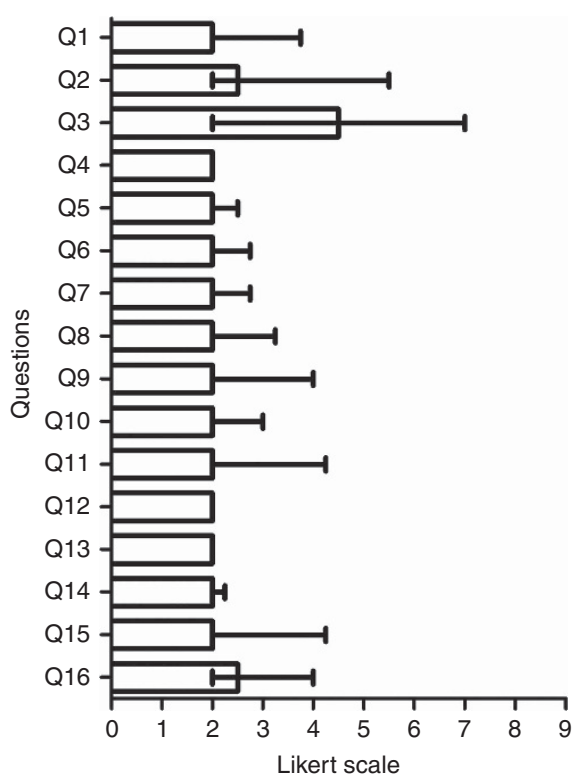

Figure 2. Statistical analysis of Endometrial Cancer Patient Data Collection Tool (ECPD), Endometrial Cancer Surgical Data Collection Tool (ECSD), Endometrial Cancer Biospecimen Tool (ECBS) and standard operating procedure for collection, processing and storage of tissue and fluid for EC research (SOP-ECBS) tools.

Score for each question in ECPD was obtained using the Likert scale, which assesses the acceptability and usability $(n=10)$. Among the panel members, only $2 \%$ were undecided on the clarity of the questions in social history section, and overall, $98 \%$ patients agreed that the tool was easy to use (Supplementary Figure S1).

ECSD collection tool. The EC surgical data (ECSD) tool included salient demographic, histological and pre/postoperative features. Demographic features such as body mass index (BMI) were included. Body mass index instead of waist-to-hip ratio or waist circumference was chosen because of its universal use and reproducibility. Although all anthropometric assessments (BMI, waist-to-hip ratio, waist and hip circumferences) are found to be strongly associated with increased risk of EC (Friedenreich et al, 2007), accurate data on waist-to-hip ratio or waist circumferences require additional effort using the same reference points by healthcare team and thus accurate data collection is unlikely to be universally feasible. In a recent study (Painter et al, 2016), BMI was 
found to be a causal factor and was associated with EC compared with waist-to-hip ratio. The preoperative imaging details are helpful to assess the spread locally and to rule out distant metastases. Discordance between endometrial biopsy and final histology results has been shown to be associated with poorer survival outcome (Werner et al, 2013); hence, preoperative biopsy results are important. Staging details including operative findings and final histopathologic details after surgery are important when correlating with outcomes. Immunohistochemical biomarkers can be used to distinguish ECs from ovarian or cervical or other malignancies, but importantly also as prognostic biomarkers that are associated with clinical outcome (Li et al, 2013; Kamal et al, 2016). Information when collected in a standard way together with biosamples will naturally increase the internal and external validity of the generated data. The patient data collection, including follow-up and accurate documentation of cause of demise, should be updated regularly until the completion of standard follow-up period (either 3 years (minimum) or 5 years, depending on local practice). The form is arranged into three sections:

(1) Surgical data: Completed at the time of sample collection.

(2) Histopathology details: Completed after final staging and treatment.

(3) Outcome data: Documented during follow-up and finally at the end of follow-up

The results of final consensus are as shown in Table 2 and Figure 2, wherein we have calculated the median with an interquartile range. There was a high level of agreement among the panellists for all sections, except that a number of the respondents considered sections on the history, antecedent biopsy details and sample collection details to be not relevant. Overall, $96.25 \%$ of panel members agreed on different aspects of the tool (Supplementary Figure S1).

EC Biospecimen tool. Variations in the collection methods and biobanking conditions (processing and storage) may alter the molecular composition, expression and stability of biomarker profile (Zander et al, 2014); thus, consistency and strict adherence to standard operating procedures is vital (Moore et al, 2011). Therefore, biobank staff with applied experience and knowledge on clinical biobanking participated in designing, revising and obtaining final consensus on the biospecimen form. Only few respondents felt that the tissue processing (both uterine and extrauterine) section of the form was difficult to understand, while all respondents agreed on the relevance and clarity of all other sections. Overall, there was a $94 \%$ level of agreement on the different aspects of this tool. The detailed results were as shown in Table 3, Figure 2 and Supplementary Figure S1.

Standard operating procedure for collection, processing and storage of tissue and fluid for EC research. Different tissue types (both uterine and extrauterine) and body fluid types are studied in EC research. The routine investigations of these biospecimens may involve extraction of protein, RNA and DNA to be evaluated using a variety of techniques such as proteomics, genomics and metabolomics. The final SOP was designed amalgamating a number of available separate, detailed methodological protocols (e.g., for centrifugation, filtration, addition of preservatives, as well as storage temperatures). Availability of such information from a biobank will allow the scientists to accurately interpret their data, for example, to examine the metabolic profile of samples such as blood, tissue, endometrial fluid or aspirate and detect diseasespecific changes with confidence, especially in multicentre studies (Assfalg et al, 2008; Bernini et al, 2009). Studies examining hormones are of major relevance to the endometrium, and in addition to more traditional samples such as blood, some have studied noninvasive specimens including saliva and urine (Shirtcliff et al, 2001). Noninvasive tests are of a particular interest in clinical research and future work is expected to focus more on them.

The outcome details of the final round of consensus regarding the standard operating procedure for collection, processing and storage of tissue and fluid for EC research (SOP-ECBS) are as presented in Table 4 and Figure 2. There was a general agreement

Table 2. Outcome of the final round of consensus for ECSD Tool using nine-point Likert scale

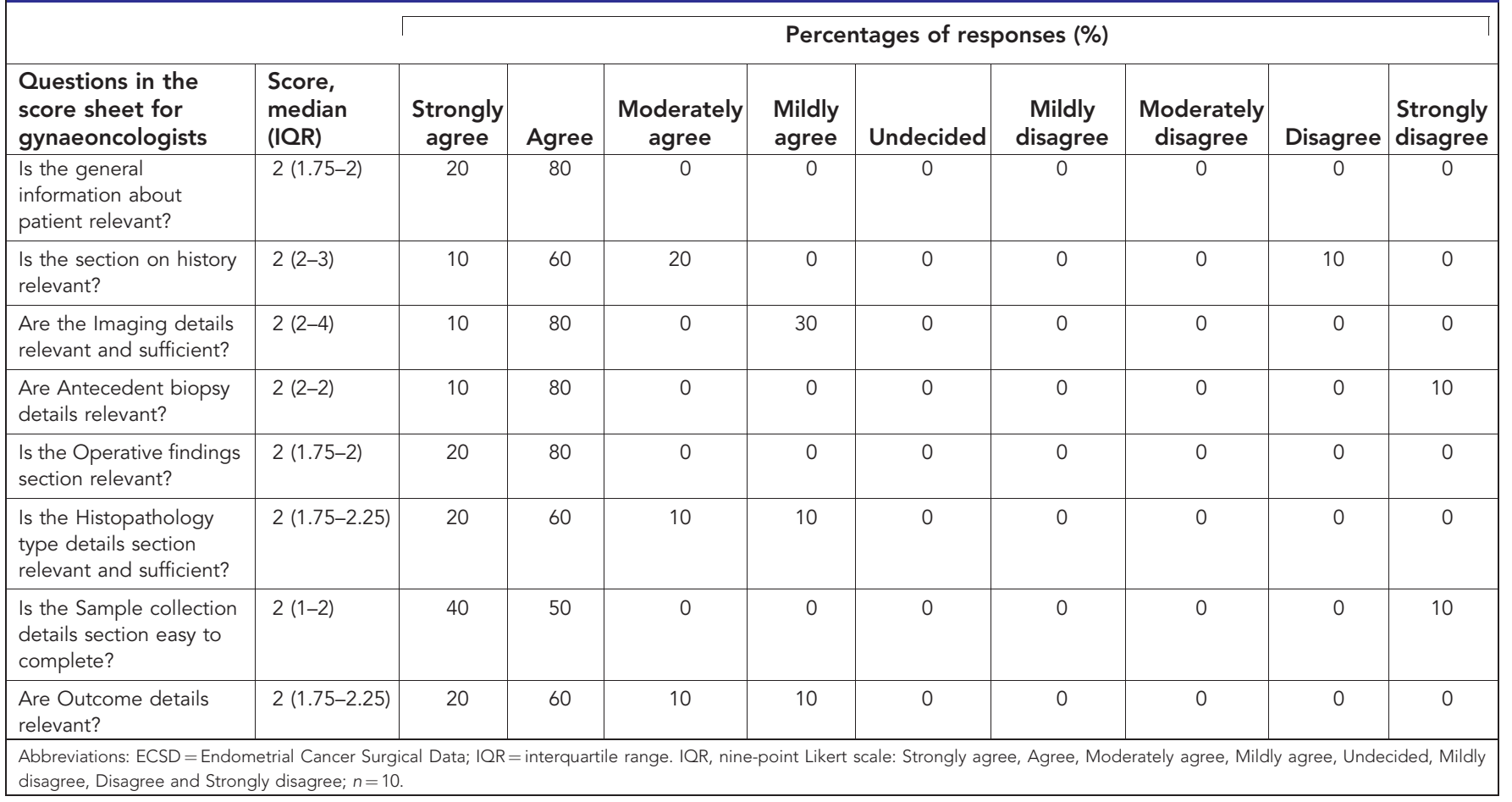


Table 3. Outcome of the final round of consensus for ECBS Tool using nine-point Likert scale

\begin{tabular}{|c|c|c|c|c|c|c|c|c|c|c|}
\hline \multirow[b]{2}{*}{$\begin{array}{l}\text { Questions in the } \\
\text { score sheet for } \\
\text { biobank staff }\end{array}$} & \multirow[b]{2}{*}{$\begin{array}{l}\text { Score } \\
\text { Median } \\
\text { (IQR) }\end{array}$} & \multicolumn{9}{|c|}{ Percentages of responses (\%) } \\
\hline & & $\begin{array}{c}\text { Strongly } \\
\text { agree }\end{array}$ & Agree & $\begin{array}{c}\text { Moderately } \\
\text { agree }\end{array}$ & $\begin{array}{l}\text { Mildly } \\
\text { agree }\end{array}$ & Undecided & $\begin{array}{c}\text { Mildly } \\
\text { disagree }\end{array}$ & $\begin{array}{c}\text { Moderately } \\
\text { disagree }\end{array}$ & Disagree & $\begin{array}{l}\text { Strongly } \\
\text { disagree }\end{array}$ \\
\hline $\begin{array}{l}\text { Sample ID-Is this } \\
\text { relevant? }\end{array}$ & $1(1-1)$ & 90 & 10 & 0 & 0 & 0 & 0 & 0 & 0 & 0 \\
\hline $\begin{array}{l}\text { Methods of tissue } \\
\text { processing } \\
\text { (Endometrium)-ls this } \\
\text { section easy to } \\
\text { understand? }\end{array}$ & $2(1-3.25)$ & 40 & 30 & 10 & 10 & 0 & 0 & 0 & 10 & 0 \\
\hline $\begin{array}{l}\text { Methods of tissue } \\
\text { processing (Extra uterine } \\
\text { tissue)-Is this section } \\
\text { easy to understand? }\end{array}$ & $2(1-3.25)$ & 40 & 30 & 10 & 10 & 0 & 0 & 0 & 10 & 0 \\
\hline $\begin{array}{l}\text { Methods of fluid } \\
\text { processing } \\
\text { (Endometrial/Peritoneal/ } \\
\text { Blood/Saliva/Urine)-ls } \\
\text { this section easy to } \\
\text { understand? }\end{array}$ & $2.5(2-4)$ & 10 & 40 & 10 & 40 & 0 & 0 & 0 & 0 & 0 \\
\hline
\end{tabular}

on the user-friendliness and relevance of the tool. Few panellists responded that tissue and blood collection details could be modified further for clarity. Overall, $83.75 \%$ of panellists agreed, $8.75 \%$ were undecided and $7.5 \%$ disagreed with different sections of this tool.

\section{DISCUSSION}

We have developed evidence-based standard data collection forms ECPD, ECSD (minimal), ECSD (Standard) and an SOP-ECBS with inclusive participation and approval of all stakeholders in EC cancer biobanking. The final tools were approved by a large multidisciplinary team of reviewers and after reaching consensus (see Supplementary Figure S1), they are published as Supplementary Information with this open access manuscript. They will therefore be freely available to all EC researchers internationally. These tools provide a means by which to reduce confounding factors in the collected data and facilitate larger multicentre studies.

Our choice of the exact information to collect was based on critical appraisal of the best available evidence. Where no published evidence was available, consultation of the experts' opinion and the SOPs of the larger biobanks were considered. The centrifugation speed in processing blood was one such example.

We have used a modified Delphi technique, with multiple alterations from the standard technique, including multiple rounds of feedback, which allows the same panel members to reassess or reconsider initial judgment, participant anonymity, controlled feedback and statistical analysis to interpret data between the rounds. Similar variations to original Delphi system, for example, restricting the ability of the experts to respond to the original question and alterations in the expert groups, as well as changing the end point, have been used previously (Thompson, 2009).

Repeated use of a homogenous panel was unjustifiable for our research aims for the following reasons. Our endeavour was to generate separate forms for diverse end points, for example, patient data collection, surgical data collection, tissue processing information and the standard operative procedures. These obviously required panel members of diverse backgrounds, with different fields of expertise and therefore our panellists were not a homogenous group.

The main deviation from the classic technique was the number of consultation rounds and the end point. Our first two rounds were descriptive to generate opinions and ideas from different expert panels. We included their feedback to generate the finalised forms and SOP. In the final round of the consensus, we distributed a score sheet to each of the panellists along with the forms to evaluate their agreement with the final tools. Our final panel included stakeholders representing those involved in all previous panels. The high percentage of agreement observed with the statistical analysis of data obtained from the third and final round precluded the need for any further consensus rounds.

As more detailed, standardised surgical data collection will allow a comprehensive assessment of the relationship between the surgical phenotypical data with the outcomes of treatments, we strongly advise the use of the standard rather than the minimal ECSD tool. However, if the collection or quality of the large set of data or specimens cannot be guaranteed, the minimal set should be employed. We plan to regularly update these tools in the future through information obtained by feedback and review of future literature, initially on a yearly basis and 5 yearly thereafter. Future considerations in the context of our initiatives include creating an internationally funded web-based central database system allowing voluntary deposition of the information on all biospecimens collected by EC researchers worldwide, which will be easily accessible to all. This approach, we believe, will reduce costs and time spent by individual units while increasing the credibility of the data generated and will offer a transparent, common platform for newer collaborations.

'Molecular Pathological Epidemiology' (MPE) integrates pathology and epidemiology to understand the interrelationships between exogenous and endogenous factors that affect carcinogenesis, progression and response to treatment. It is a constantly evolving field in cancer research (Ogino and Stampfer, 2010). Statistical methods have also been developed to consider both molecular pathology and epidemiology to ensure novel discoveries with high clinical impact. However, the generation of such highimpact MPE studies are impeded by similar challenges including 
Table 4. Outcome of the final round of consensus for SOP-ECBS Tool using nine-point Likert scale

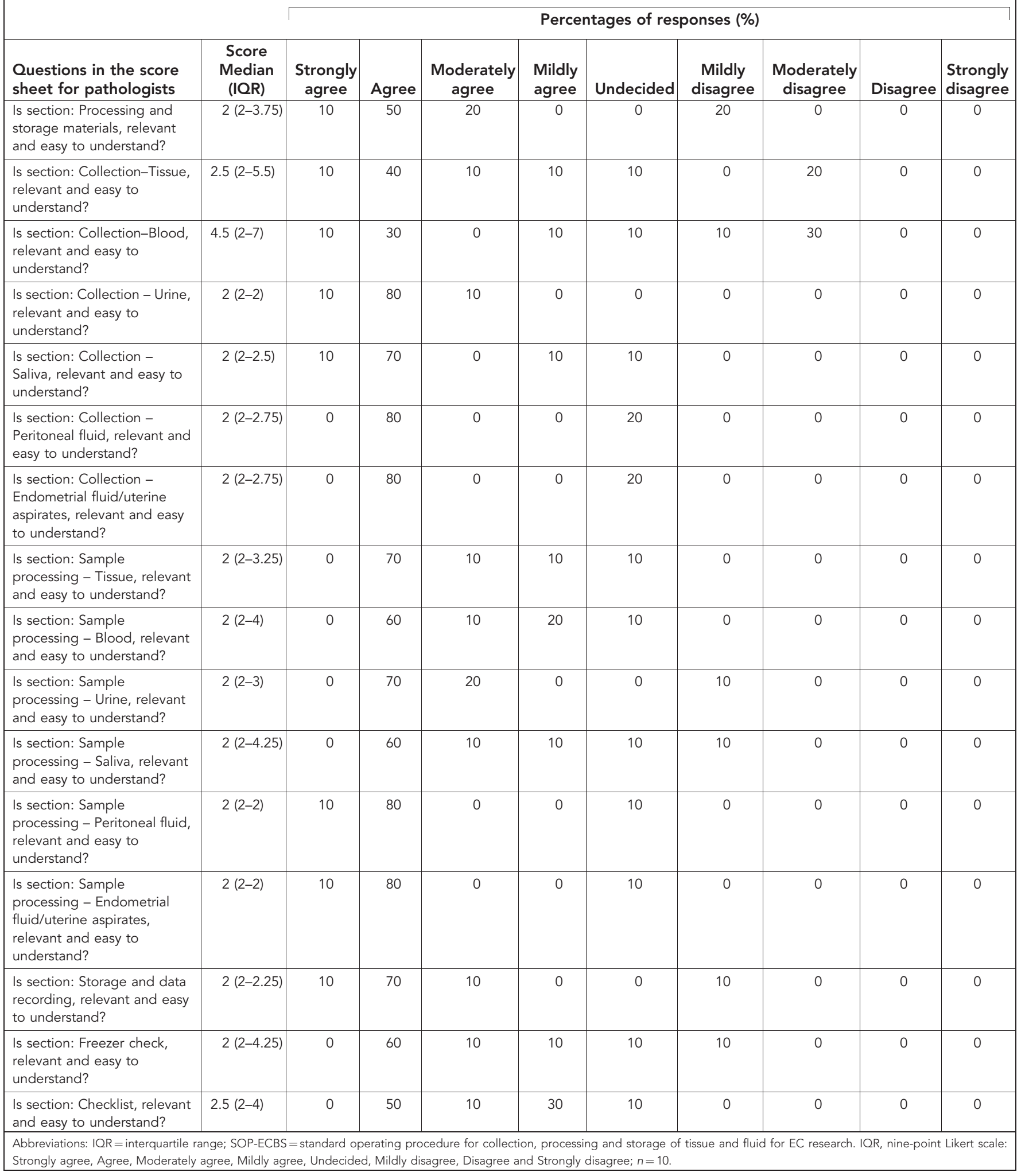

selection and recall bias, measurement errors and misclassification comparable to the traditional molecular biological studies (Hughes et al, 2012; Campbell et al, 2017). Variability in tissue retrieval rate and sample sizes leads to random and non-random selection bias, resulting in large variation of an effect estimate with wide confidence intervals and publication bias (Ogino et al, 2011,
2016). The use of our tools by EC biobanks will provide means with which to streamline the collection of a large amount of standardised quality assured material from well-phenotyped patients. This will in turn facilitate adequately powered studies, giving high clinical impact while also facilitating high-quality research that is attainable within an acceptable timescale. 


\section{ACKNOWLEDGEMENTS}

We acknowledge the support from Liverpool Women's NHS Foundation Trust (MA/DKH) and Institute of Translational Medicine at the University of Liverpool (DKH/MA). We are grateful to Liverpool Women's Hospital Gynaeoncology Oncology Department, ENITEC, Dr Steven Lane and all panel members for reviewing the forms and providing feedback. The support received from Dr Nicola Tempest, Jo Drury in preparation of this manuscript, and Druvi Edirisinghe for proof reading is also acknowledged.

\section{CONFLICT OF INTEREST}

The authors declare no conflict of interest.

\section{REFERENCES}

Assfalg M, Bertini I, Colangiuli D, Luchinat C, Schäfer H, Schütz B, Spraul M (2008) Evidence of different metabolic phenotypes in humans. Proc Natl Acad Sci USA 105(5): 1420-1424.

Beral V, Bull D, Reeves G, Collaborators MWS (2005) Endometrial cancer and hormone-replacement therapy in the Million Women Study. Lancet 365(9470): 1543-1551.

Bergman L, Beelen ML, Gallee MP, Hollema H, Benraadt J, van Leeuwen FE (2000) Risk and prognosis of endometrial cancer after tamoxifen for breast cancer. Comprehensive Cancer Centres' ALERT Group. Assessment of Liver and Endometrial cancer Risk following Tamoxifen. Lancet 356(9233): 881-887.

Bernini P, Bertini I, Luchinat C, Nepi S, Saccenti E, Schäfer H, Schütz B, Spraul M, Tenori L (2009) Individual human phenotypes in metabolic space and time. J Proteome Res 8(9): 4264-4271.

Boilesen AE, Bisgaard ML, Bernstein I (2008) Risk of gynecologic cancers in Danish hereditary non-polyposis colorectal cancer families. Acta Obstet Gynecol Scand 87(11): 1129-1135.

Campbell PT, Rebbeck TR, Nishihara R, Beck AH, Begg CB, Bogdanov AA, Cao Y, Coleman HG, Freeman GJ, Heng YJ, Huttenhower C, Irizarry RA, Kip NS, Michor F, Nevo D, Peters U, Phipps AI, Poole EM, Qian ZR, Quackenbush J, Robins H, Rogan PK, Slattery ML, Smith-Warner SA, Song M, VanderWeele TJ, Xia D, Zabor EC, Zhang X, Wang M, Ogino S (2017) Proceedings of the third international molecular pathological epidemiology (MPE) meeting. Cancer Causes Control 28(2): 167-176.

CRUK. Uterine Cancer Statistics, Vol. 2015. Available at: http:// www.cancerresearchuk.org/health-professional/cancer-statistics/statisticsby-cancer-type/uterine-cancer.

Elliott P, Peakman TC, Biobank U (2008) The UK Biobank sample handling and storage protocol for the collection, processing and archiving of human blood and urine. Int J Epidemiol 37(2): 234-244.

Fassbender A, Rahmioglu N, Vitonis AF, Vigano P, Giudice LC, D’Hooghe TM, Hummelshoj L, Adamson GD, Becker CM, Missmer SA, Zondervan KT, Group WEW (2014) World Endometriosis Research Foundation Endometriosis Phenome and Biobanking Harmonisation Project: IV. Tissue collection, processing, and storage in endometriosis research. Fertil Steril 102(5): 1244-1253.

Fearnley EJ, Marquart L, Spurdle AB, Weinstein P, Webb PM, Australian Ovarian Cancer Study Group and Australian National Endometrial Cancer Study Group (2010) Polycystic ovary syndrome increases the risk of endometrial cancer in women aged less than 50 years: an Australian case-control study. Cancer Causes Control 21(12): 2303-2308.

Ferlay J, Soerjomataram I, Dikshit R, Eser S, Mathers C, Rebelo M, Parkin DM, Forman D, Bray F (2015) Cancer incidence and mortality worldwide: sources, methods and major patterns in GLOBOCAN 2012 Int J Cancer 136(5): E359-E386.

Friberg E, Orsini N, Mantzoros CS, Wolk A (2007) Diabetes mellitus and risk of endometrial cancer: a meta-analysis. Diabetologia 50(7): 1365-1374.

Friedenreich C, Cust A, Lahmann PH, Steindorf K, Boutron-Ruault MC, Clavel-Chapelon F, Mesrine S, Linseisen J, Rohrmann S, Boeing H, Pischon T, Tjønneland A, Halkjaer J, Overvad K, Mendez M, Redondo ML, Garcia CM, Larrañaga N, Tormo MJ, Gurrea AB, Bingham S, Khaw KT, Allen N, Key T, Trichopoulou A, Vasilopoulou E,
Trichopoulos D, Pala V, Palli D, Tumino R, Mattiello A, Vineis P, Bueno-de-Mesquita HB, Peeters PH, Berglund G, Manjer J, Lundin E, Lukanova A, Slimani N, Jenab M, Kaaks R, Riboli E (2007) Anthropometric factors and risk of endometrial cancer: the European prospective investigation into cancer and nutrition. Cancer Causes Control 18(4): 399-413.

Gong TT, Wang YL, Ma XX (2015) Age at menarche and endometrial cancer risk: a dose-response meta-analysis of prospective studies. Sci Rep 5: 14051.

Gynae Clinical Network Constitution (2014-2015) Available at: http://www. nwcscnsenate.nhs.uk/files/2314/1172/3867/Gynae_CNG_Constitution_ 2014.pdf.

Heravi-Moussavi A, Anglesio MS, Cheng SW, Senz J, Yang W, Prentice L, Fejes AP, Chow C, Tone A, Kalloger SE, Hamel N, Roth A, Ha G, Wan AN, Maines-Bandiera S, Salamanca C, Pasini B, Clarke BA, Lee AF, Lee CH, Zhao C, Young RH, Aparicio SA, Sorensen PH, Woo MM, Boyd N, Jones SJ, Hirst M, Marra MA, Gilks B, Shah SP, Foulkes WD, Morin GB, Huntsman DG (2012) Recurrent somatic DICER1 mutations in nonepithelial ovarian cancers. $N$ Engl J Med 366(3): 234-242.

Hughes LA, Williamson EJ, van Engeland M, Jenkins MA, Giles GG, Hopper JL, Southey MC, Young JP, Buchanan DD, Walsh MD, van den Brandt PA, Alexandra Goldbohm R, Weijenberg MP, English DR (2012) Body size and risk for colorectal cancers showing BRAF mutations or microsatellite instability: a pooled analysis. Int J Epidemiol 41(4): 1060-1072.

International Society for Biological and Environmental Repositories (2008) Best Practices for Respositories: Collection, Storage, Retrieval and Distribution of Biological Materials for Research. In Cell preservation technology, Vol 6, 2nd edition. Mary Ann Liebert, Inc.: New Rochelle, NY, USA.

Kamal A, Tempest N, Parkes C, Alnafakh R, Makrydima S, Adishesh M, Hapangama DK (2016) Hormones and endometrial carcinogenesis. Horm Mol Biol Clin Invest 25(2): 129-148.

Kandoth C, Schultz N, Cherniack AD, Akbani R, Liu Y, Shen H, Robertson AG, Pashtan I, Shen R, Benz CC, Yau C, Laird PW, Ding L, Zhang W, Mills GB, Kucherlapati R, Mardis ER, Levine DA, Network CGAR (2013) Integrated genomic characterization of endometrial carcinoma. Nature 497(7447): 67-73.

Li MZL, Qi W, Shen D, Li X, Wang J, Wei L (2013) Clinical implications and prognostic value of five biomarkers in endometrial carcinoma. Chin-German J Clinl Oncol 12(12): 586-591.

Lindemann K, Eskild A, Vatten LJ, Bray F (2010) Endometrial cancer incidence trends in Norway during 1953-2007 and predictions for 2008-2027. Int J Cancer 127(11): 2661-2668.

Lindemann K, Vatten LJ, Ellstrøm-Engh M, Eskild A (2008) Body mass, diabetes and smoking, and endometrial cancer risk: a follow-up study. $\mathrm{Br} \mathrm{J}$ Cancer 98(9): 1582-1585.

Moore HM, Kelly A, Jewell SD, McShane LM, Clark DP, Greenspan R, Hainaut P, Hayes DF, Kim P, Mansfield E, Potapova O, Riegman P, Rubinstein Y, Seijo E, Somiari S, Watson P, Weier HU, Zhu C, Vaught J (2011) Biospecimen reporting for improved study quality. Biopreserv Biobank 9(1): 57-70.

Morente MM, de Alava E, Fernandez PL (2007) Tumour banking: the Spanish design. Pathobiology 74(4): 245-250.

National Cancer Institute (2011) Best Practices For Biospecimen Resources. NIH: Bethesda, MD, USA. Available at: https://biospecimens.cancer.gov/ practices/2011bp.asp.

National Cancer Institute (2016) Best Practices For Biospecimen Resources. NIH: Bethesda, MD, USA. Available at: https://biospecimens.cancer.gov/ bestpractices/2016-NCIBestPractices.pdf.

NCIN (2013) Outline of Uterine Cancer in the United Kingdom: Incidence, Mortality and Survival. NCIN. PHE Knowledge and Intelligence Team (East Midlands): Sheffield, UK.

Ogino S, Chan AT, Fuchs CS, Giovannucci E (2011) Molecular pathological epidemiology of colorectal neoplasia: an emerging transdisciplinary and interdisciplinary field. Gut 60(3): 397-411.

Ogino S, Nishihara R, VanderWeele TJ, Wang M, Nishi A, Lochhead P, Qian ZR, Zhang X, Wu K, Nan H, Yoshida K, Milner Jr DA, Chan AT, Field AE, Camargo Jr CA, Williams MA, Giovannucci EL (2016) Review article: the role of molecular pathological epidemiology in the study of neoplastic and non-neoplastic diseases in the era of precision medicine. Epidemiology 27(4): 602-611.

Ogino S, Stampfer M (2010) Lifestyle factors and microsatellite instability in colorectal cancer: the evolving field of molecular pathological epidemiology. J Natl Cancer Inst 102(6): 365-367. 
Painter JN, O’Mara TA, Marquart L, Webb PM, Attia J, Medland SE, Cheng T, Dennis J, Holliday EG, McEvoy M, Scott RJ, Ahmed S, Healey CS, Shah M, Gorman M, Martin L, Hodgson SV, Beckmann MW, Ekici AB, Fasching PA, Hein A, Rübner M, Czene K, Darabi H, Hall P, Li J, Dörk T, Dürst M, Hillemanns P, Runnebaum IB, Amant F, Annibali D, Depreeuw J, Lambrechts D, Neven P, Cunningham JM, Dowdy SC, Goode EL, Fridley BL, Winham SJ, Njølstad TS, Salvesen HB, Trovik J, Werner HM, Ashton KA, Otton G, Proietto A, Mints M, Tham E, Bolla MK, Michailidou K, Wang Q, Tyrer JP, Hopper JL, Peto J, Swerdlow AJ, Burwinkel B, Brenner H, Meindl A, Brauch H, Lindblom A, Chang-Claude J, Couch FJ, Giles GG, Kristensen VN, Cox A, Pharoah PD, Tomlinson I, Dunning AM, Easton DF, Thompson DJ, Spurdle AB, Group A, RENDOCAS f, (NSECG) NSoECGG, (ANECS) ANECSG (2016) Genetic risk score Mendelian randomization shows that obesity measured as body mass index, but not waist:hip ratio, is causal for endometrial cancer. Cancer Epidemiol Biomarkers Prev 25(11): 1503-1510.

Rahmioglu N, Fassbender A, Vitonis AF, Tworoger SS, Hummelshoj L, D'Hooghe TM, Adamson GD, Giudice LC, Becker CM, Zondervan KT, Missmer SA, Group WEW (2014) World Endometriosis Research Foundation Endometriosis Phenome and Biobanking Harmonization Project: III. Fluid biospecimen collection, processing, and storage in endometriosis research. Fertil Steril 102(5): 1233-1243.

Ransohoff DF, Gourlay ML (2010) Sources of bias in specimens for research about molecular markers for cancer. J Clin Oncol 28(4): 698-704.

Schonfeld SJ, Hartge P, Pfeiffer RM, Freedman DM, Greenlee RT, Linet MS, Park Y, Schairer C, Visvanathan K, Lacey JV (2013) An aggregated analysis of hormonal factors and endometrial cancer risk by parity. Cancer 119(7): 1393-1401.

Sheldon E, Vo KC, McIntire RA, Aghajanova L, Zelenko Z, Irwin JC, Giudice LC (2011) Biobanking human endometrial tissue and blood specimens: standard operating procedure and importance to reproductive biology research and diagnostic development. Fertil Steril 95(6): 2120-2122.e1-e12.

Shirtcliff EA, Granger DA, Schwartz E, Curran MJ (2001) Use of salivary biomarkers in biobehavioral research: cotton-based sample collection methods can interfere with salivary immunoassay results. Psychoneuroendocrinology 26(2): 165-173.

Thompson M (2009) Considering the implication of variations within Delphi research. Fam Pract 26(5): 420-424.

Tworoger SS, Hankinson SE (2006) Use of biomarkers in epidemiologic studies: minimizing the influence of measurement error in the study design and analysis. Cancer Causes Control 17(7): 889-899.

Vaught J, Lockhart NC (2012) The evolution of biobanking best practices. Clin Chim Acta 413(19-20): 1569-1575.

Vitonis AF, Vincent K, Rahmioglu N, Fassbender A, Buck Louis GM, Hummelshoj L, Giudice LC, Stratton P, Adamson GD, Becker CM, Zondervan KT, Missmer SA, Group WEW (2014) World Endometriosis Research Foundation Endometriosis Phenome and Biobanking Harmonization Project: II. Clinical and covariate phenotype data collection in endometriosis research. Fertil Steril 102(5): 1223-1232.

Werner HMJ, Trovik J, Marcickiewicz J, Tingulstad S, Staff AC, Engh ME, Oddenes K, Rokne JA, Tjugum J, Lode MS, Amant F, Salvesen HB (2013) A discordant histological risk classification in preoperative and operative biopsy in endometrial cancer is reflected in metastatic risk and prognosis. Eur J Cancer 49: 625-632.

Wiegand KC, Shah SP, Al-Agha OM, Zhao Y, Tse K, Zeng T, Senz J, McConechy MK, Anglesio MS, Kalloger SE, Yang W, Heravi-Moussavi A, Giuliany R, Chow C, Fee J, Zayed A, Prentice L, Melnyk N, Turashvili G, Delaney AD, Madore J, Yip S, McPherson AW, Ha G, Bell L, Fereday S, Tam A, Galletta L, Tonin PN, Provencher D, Miller D, Jones SJ, Moore RA, Morin GB, Oloumi A, Boyd N, Aparicio SA, Shih IeM, Mes-Masson AM, Bowtell DD, Hirst M, Gilks B, Marra MA, Huntsman DG (2010) ARID1A mutations in endometriosis-associated ovarian carcinomas. N Engl J Med 363(16): 1532-1543.

Yuille M, van Ommen GJ, Bréchot C, Cambon-Thomsen A, Dagher G, Landegren U, Litton JE, Pasterk M, Peltonen L, Taussig M, Wichmann HE, Zatloukal K (2008) Biobanking for Europe. Brief Bioinform 9(1): 14-24.

Zander J, Bruegel M, Kleinhempel A, Becker S, Petros S, Kortz L, Dorow J, Kratzsch J, Baber R, Ceglarek U, Thiery J, Teupser D (2014) Effect of biobanking conditions on short-term stability of biomarkers in human serum and plasma. Clin Chem Lab Med 52(5): 629-639.

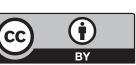
of this licen

(C) The Author(s) named above 2017

Supplementary Information accompanies this paper on British Journal of Cancer website (http://www.nature.com/bjc) 